\title{
«Decadencia» y «Tiranía»: Textos, lenguajes y representaciones de la proclamación de D. João IV en el Estado de la India ${ }^{1}$
}

\author{
JosÉ FERREIRA ${ }^{2}$ \\ Centro de História de Além-Mar
}

\begin{abstract}
«Decadence» and «Tyranny»: Texts, languages and representations of the proclamation of D. João IV in the State of India
\end{abstract}

\begin{abstract}
RESUMEN
¿Cómo fue interpretada y justificada en la India la revuelta que dictó el fin de la Unión Dinástica? Esta interrogación será, en líneas generales, el hilo conductor de este texto, que busca explorar las dinámicas globales de la Restauración de 1640. Así, a lo largo de las siguientes páginas, se intenta analizar la constitución de un corpus documental formado por cartas, sermones y relatos de la proclamación, recuperando el vocabulario político que componía estos

discursos y pensando la forma en que estos presentaban una lectura de la historia reciente del Estado de la India a través de la cual procuraban legitimar la ruptura con la Monarquía Hispánica.
\end{abstract}

\section{PALABRAS CLAVE:}

Estado de la India, Restauração, Unión de Coronas, Cultura Política, Tiranía y Decadencia.

\begin{abstract}
How was perceived in India the rebellion that put an end the Union of the Portuguese and Spanish Crowns? This question will be the guiding line of this article, which aims to understand the global dynamics of the Restauração of 1640. Throughout the next few pages, we seek to analyze the constitution of a documental corpus composed by letters, sermons and festival descriptions, interpreting both the political language adopted by these discourses and the view of the history of the «Estado da Índia» through which they sought to legitimize the rebellion.
\end{abstract}

\section{KEY WORDS:}

Estado da Índia; Restauração, Union of the Crowns, Political Culture, Tyranny and Decay.

1 Este estudio es la versión corregida y incrementada de un texto presentado en el Congreso Internacional de las Monarquías Ibéricas: Barroco y Globalización (1580-1715), Madrid, 21-22 de noviembre de 2012. Traducción del portugués a cargo de Alberto Guerra.

2 José Ferreira. Investigador del Centro de História de Além-mar (FCSH-UNL/UAç). Becario del proyecto de investigación «Colonial Mimesis in Lusophone Asia and Africa» (FCT, PTDC/CSANT/101064/2008). 
A mediados de octubre de 1641, una curiosa procesión recorrió las calles de Santa Cruz de Cochín, en la costa occidental de la India. En cabeza iban los oficiales de la ciudad con sus banderas, acompañados por danzas y por todo género de algazaras. Un poco detrás, en compañía de los religiosos de San Francisco, San Agustín y Santo Domingo, seguía una carroza triunfante, sobre la cual había sido colocada una figura que pretendía representar la majestad de D. João IV sentado en un trono cubierto por un dosel. Saliendo de la Catedral, este cortejo recorrió las principales calles de la ciudad, en las que se habían levantado arcos triunfales ricamente decorados y adornados con motivos heroicos. Los habitantes de Cochín demostraban así públicamente su alegría por las noticias llegadas del reino, que se hacían eco de la revuelta del $1^{\circ}$ de Diciembre de 1640 y de la proclamación de D. João, Duque de Braganza, como rey de Portugal.

La descripción de estas ceremonias consta en una relación dedicada al monarca recién aclamado y titulada Trivmfos festivaes da insigne e nobre Cidade da Santa Crux de Cochim, nas alegres nouas da gloriosa acclamaçaõ \& alçamento del Rey nosso Senhor Dom loão o Quarto de Portugal, obra del oidor de la ciudad, Agostinho de Almeida Gato ${ }^{3}$. Este extraordinario manuscrito, que hoy se encuentra en la Biblioteca Pública de Évora, me parece un buen punto de partida para las reflexiones que este estudio procura desarrollar acerca de las repercusiones ultramarinas de la Restauración de 1640 y de la forma como la ruptura con la monarquía hispánica fue recibida y justificada en el Estado de la India.

Si, como presupone Serge Gruzinski en su libro Les Quatre Parties du Monde, el año 1640 representó el fin de un mosaico planetario caracterizado por la circulación de gentes, mercancías e ideas a lo largo y ancho de los territorios por los que se extendía la monarquía hispánica ${ }^{4}$, la verdad es que ese epílogo ilustra de una forma ejemplar la telaraña de conexiones globales inaugurada por los imperios ibéricos. De hecho, asegurar la lealtad de todos los territorios bajo jurisdicción portuguesa era uno de los principales retos a los que se enfrentaba la nueva dinastía, en un momento en que el éxito de la revuelta todavía estaba lejos de ser evidente. Siendo así, a partir de principios de 1641, los ecos de la rebelión alcanzaron progresivamente las plazas ultramarinas de ambas coronas, circulando a través de diversos canales de comunicación e información. Desde Brasil al extremo Oriente, las nuevas de Portugal suscitaron el entusiasmo de unos, las dudas de otros y - como demostró Stuart Schwartz para el caso de la América española $\mathrm{a}^{5}$ - provocaron verdaderos brotes de pánico en algunas partes del imperio de los Austrias.

La historia de cómo fue recibida la noticia de la sublevación en las conquistas asiáticas de la corona de Portugal continúa siendo, empero, un tema relativamen-

\footnotetext{
3 Biblioteca Pública y Arquivo Distrital de Évora, Mss., Códice CXVI/1-23.

GRUZINSKI, 2004, 29/32.

5 SCHWARTZ, 2003, 185/215. LAVALLÉ, 2007, 181/203.
} 
te inexplorado. Si exceptuamos los trabajos de Edval de Souza Barros y Rafael Valladares ${ }^{6}$, son escasos los estudios recientes que abordan este periodo de la historia del Estado de la India. ¿Cómo entender este silencio? Por un lado, esta indiferencia podrá deberse al propio éxito que, visto a posteriori, alcanzó el movimiento restaurador. Este desenlace acabaría de este modo por «naturalizarse», convirtiéndose en un dato adquirido y raras veces cuestionado. Por otro, la verdad es que 1640 parecía inscribirse en un tiempo en que Asia habría pasado a un segundo plano en el ámbito del imperio portugués, ante la nueva primacía de Brasil. Siendo así, en la senda de la hipótesis formulada por Jaime Cortesão ${ }^{7}$, los años de agregación a la monarquía hispánica habrían asistido a una transformación del paradigma económico y geográfico del imperio portugués, que dejaba de ser fundamentalmente asiático para centrarse en el Atlántico y, sobre todo, en Brasil.

No obstante, a pesar de las urgencias que se abatían sobre el reino durante los meses que siguieron al golpe de estado, la verdad es que la nueva casa real desde muy pronto se preocupó con la necesidad de garantizar la fidelidad de los portugueses que servían en Oriente, enviando a Goa los avisos de la proclamación de D. João IV. Sin embargo, las largas distancias que separaban las plazas portuguesas en Asia y las condicionantes asociadas al régimen de monzones representaban un importante obstáculo a la circulación de la información en el Estado de la India. Así se explica que la divulgación de las noticias de la revuelta se haya prolongado en el tiempo, entre el reconocimiento del nuevo rey en la isla de Mozambique, en agosto de 1641, y la llegada de las noticias a Macao, en el mes de mayo del año siguiente.

Las ceremonias de proclamación de D. João IV, reproducidas y escenificadas en cada plaza y fortaleza — como nos relata el oidor de Cochín-, son por ventura el signo más evidente de este proceso de «mundialización» de la revuelta. Pero el anuncio de los acontecimientos de Lisboa fue también acompañado por una intensa actividad propagandística, asistiéndose a lo largo de la primera mitad de la década de 1640 a una multiplicación de los discursos destinados a legitimar la ruptura con la monarquía hispánica. Vinculándose al pensamiento político del mundo católico postridentino y adoptando su vocabulario político, los publicistas de la Restauração participaban así en un combate que les oponía a quienes acusaban al Duque de Braganza de usurpar el trono portugués. En forma de cartas, sermones, panfletos o relatos de las ceremonias, estas configuraciones discursivas heterogéneas produjeron diversas imágenes sobre el Estado de la India, repensando su historia reciente a la luz de la necesidad de justificar la secesión de la corona de Portugal.

6 BARROS, 2008. VALLADARES, 2001.

7 CORTESÃO, 1984, 46/66. 
Sería obviamente ingenuo buscar en estos textos la clave para descodificar las razones que llevaron a la India portuguesa a sumarse al movimiento restaurador. Pero, como recordó Quentin Skinner, la elección de un determinado lenguaje para justificar una acción es todo menos inocente, no pudiendo ser desvinculada del contexto, la cultura política y las disputas locales que la enmarcan ${ }^{8}$. La movilización de argumentos históricos, identitarios y mesiánicos — que caracteriza los discursos de la propaganda restauradora - puede así ser encarada como una tentativa de conferir autoridad y legitimidad a opciones y modos de actuación que estaban lejos de ser naturales o incontestados. Partiendo de esta relación entre la acción política y los discursos que la legitiman, el ejercicio que se propone es el de pensar la recurrencia de un léxico alusivo a la «decadencia» del imperio portugués y a la "tiranía de Castilla», cuestionando la forma como este vocabulario interpelaba la coyuntura vivida en el Estado de la India y lo que nos puede revelar sobre las estrategias discursivas de sus autores.

\section{¿BAJO EL SIGNO DE LA DECADENCIA?}

Regresemos, por ahora, a los Trivmfos festivaes da insigne nobre Cidade da Santa Crux de Cochim. Ya en el primer capítulo de su texto, Agostinho de Almeida Gato afirmaba que, para poder dar cuenta de la alegría con que las nuevas de la Restauración habían sido festejadas, le era necesario describir primeramente «el miserable estado en que se veía la ciudad de Cochín cuando a ella llegó la milagrosa nueva de la sucesión de la Majestad del Rey Dom João el cuarto». Procede, entonces, a trazar un retrato dramático de la pobreza de una ciudad que otrora se contaba entre las más ricas de la India, evocando «los barrios todos despoblados", las «muchas matronas que habían sido criadas con todas las delicias y riquezas y se veían andar por las puertas mendigando" y las mujeres que "entregaban sus cuerpos a quien les diera con lo que pudieran sustentarse». Relataba asimismo cómo los propios oficiales del cabildo se habían visto obligados a empeñar una cruz de plata, únicamente para poder mandar hacer la bandera con la que se procedería a la proclamación pública y solemne del nuevo rey ${ }^{9}$.

El oidor de Cochín no era, con todo, el único en disertar de forma pesimista sobre la coyuntura que atravesaba la India. Manuel Jacome de Mesquita, autor de un relato de las fiestas de proclamación de D. João IV en Goa —publicado en esa misma ciudad el año 1643 - afirmaba igualmente que «el estado en que éste de la India se veía era extremo y lastimoso, no desemejante de aquel del que el reino de Portugal se lamentaba, sino que podíamos afirmar, ser muchas más en número, y mayores en su calidad, las miserias que acompañaban y atribulaban a los

8 SKINNER, 2005, 203/220.

9 Biblioteca Pública y Arquivo Distrital de Évora, Mss., Códice CXVI/1-23, fol. 4-5v. 
que en estas partes tan alejadas vivían ${ }^{10}$. Opinión semejante tenía Manuel Borges de Corte Real, edil municipal de Goa, quien en una carta enviada al reino se lamentaba diciendo que «las cosas de este estado están en lo más miserable que imaginar se puede y que fuera más fácil a nuestros antepasados creer que esto se perdía que cuidar que llegaría a tal estado»"11.

La imagen de una Asia portuguesa que caminaba hacia el colapso estaba, sin embargo, lejos de representar una novedad absoluta. Al menos desde finales del siglo XVI todo un género literario, inspirado por los textos de arbitrios y advertencias que entonces proliferaban en la Península Ibérica, se dedicaba a la denuncia de los «males» que afectaban al Estado de la India y a la propuesta de «remedios» susceptibles de mitigarlos. Tópicos como la corrupción, la disolución moral de quienes servían en Oriente, o la pérdida de reputación de las armas portuguesas, eran algunos de los blancos predilectos de estos autores, entre quienes se contaban hombres como Diogo do Couto y Francisco Rodrigues da Silveira ${ }^{12}$. Por otra parte, lejos de ser exclusiva de los autores portugueses, esta imagen de declive también era reproducida por los relatos de viajeros extranjeros. Es el caso del aventurero francés Jean-Baptiste Tavernier, quien, tras visitar Goa a mediados de la década de 1640, se confesó sorprendido al contemplar hasta qué punto la ciudad había decaído en relación a su antiguo esplendor ${ }^{13}$.

Este recurso casi obsesivo a un vocabulario vinculado a la idea de «decadencia” parece haber adquirido una urgencia redoblada en las décadas de 1620 y 1630 , como respuesta a las crecientes amenazas a las que deben enfrentarse los portugueses en Asia, sobre todo a causa de las arremetidas de los «rebeldes de Europa», británicos y holandeses. La caída de la fortaleza portuguesa de Ormuz - una de las factorías comerciales más ricas de Asia-, ante los esfuerzos coaligados del Imperio Safávida y de la East India Company, podría así ser evocada como un hito simbólico de dos de los principales desafíos a los que el Estado de la India se enfrentaba en ese momento: la reconfiguración del espacio político asiático y la competencia de los rivales europeos ${ }^{14}$. Tradicionalmente encarada como un hecho incuestionable por la historiografía portuguesa e internacional, esta imagen de un Estado de la India en profunda e irreversible decadencia ha sido relativizada por algunos estudios recientes, que han llamado la atención acerca de los matices de este retroceso, subrayando la capacidad de reacción y la adaptación de los intereses portugueses en Asia ${ }^{15}$.

Sin embargo, este cuestionamiento no implica que la «decadencia» pueda ser reducida a una mera construcción historiográfica. La frecuencia con la que surge

10 BOXER, 1932, 15.

1 Arquivo Histórico Ultramarino (Lisboa), Conselho Ultramarino, Índia, caja. 26, doc. 1.

12 WINIUS, 1994. CHATURVEDULA, 2010, 27/59.

13 TAVERNIER, 1676 2, lib. 1, 115/124.

14 SUBRAHMANYAM, 1995, 207/215.

15 AMES, 2000. 
en las fuentes contemporáneas sugiere que esta imagen era una parte importante de la forma como sus autores percibían la situación vivida, inscribiéndola en una dicotomía que oponía un presente de ruina y miseria a un tiempo ideal proyectado en el pasado. El hecho de que en dicha supuesta era de apogeo se hicieran oír quejas del mismo jaez, lamentando la falta de efectivos militares y la fragilidad de las posiciones portuguesas ${ }^{16}$, no disminuye la relevancia de estos tópicos ni su impacto en el lenguaje político a través del cual el Estado de la India era imaginado. En cualquier caso, el juego entre la percepción de declive y la acción política a través de la cual se procuraba responder a esta percepción —clave analítica de un importante artículo de John Elliott ${ }^{17}$ - , con frecuencia podría ocultar estrategias particulares, tanto por parte de los autores que afirmaban conocer la clave para remediar la situación, como por parte de los grupos e instituciones locales que buscaban obtener el favor regio.

Adoptada por un variadísimo abanico de discursos a lo largo de las décadas que antecedieron la sublevación de Portugal, la argumentación en torno a la declinación del Estado de la India ganó un nuevo protagonismo al ser recuperada por los autores que buscaban legitimar la nueva situación política. Retratando la ruina de ciudades como Goa y Cochín y describiendo la extrema pobreza que padecían sus habitantes, los relatos de Agostinho de Almeida Gato y Manuel Jacome de Mesquita presentaban a los portugueses de la India como humildes vasallos cuyas necesidades habían sido descuidadas por los monarcas de la casa de Austria.

El recurso a estas categorías podría entonces servir un doble propósito. Por un lado, permitía representar ante el nuevo monarca las miserias con las que se veían confrontados quienes servían en Oriente y la esperanza que tenían de ser socorridos por su rey natural, confiriendo un peso adicional a los pedidos de auxilio y de concesión de mercedes. Sus argumentos se aproximaban, de este modo, a un conjunto de valores profundamente enraizados en la cultura política europea, relacionados con el ideal del «buen gobierno» y con la figura de un rey paternal que gobernaba con justicia y magnanimidad. Pero, por otro lado, la utilización de este lenguaje reforzaba la idea de que el gobierno Habsburgo había sido tiránico y de que había llevado a la India a la ruina, legitimando así —en términos que podrían ser reconocidos por su audiencia - la ruptura con la monarquía hispánica y la subsiguiente proclamación de D. João IV como rey de Portugal.

\section{REYES TIRANOS, SEÑORES DEL MUNDO}

Considerado como el origen de todas las miserias del Estado de la India, la tiranía con la que los Austrias habían gobernado el reino de Portugal ocupaba, de este modo, un lugar protagonista en el léxico político coevo, convirtiéndose en una

16 XAVIER, 2008, 37/80.

17 ELLIOTT, 1977, 41/61. 
de las configuraciones discursivas más comunes en el repertorio de los publicistas de la Restauração. Remitiendo a un vocabulario doctrinario específico ${ }^{18}$, las referencias a la «tiranía de Castilla» pretendían justificar la sucesión alegando que, durante los años de unión de las coronas ibéricas, las plazas asiáticas habían sido dejadas al abandono, los equilibrios tradicionales de poder subvertidos y las libertades de los vasallos quebrantadas. La insistencia en este tópico, como todo lo que revelaba sobre la forma como deberían funcionar las relaciones entre el rey y sus vasallos, permitía presentar el golpe de 1640 como la reposición de un orden natural, que habría sido interrumpido por los «sesenta años de cautiverio» a los que tanto Portugal como sus conquistas ultramarinas habrían sido sometidos.

En parte, esta argumentación pasaba por la construcción de una narrativa sobre la historia de la presencia portuguesa en Asia, en la que 1580 y 1640 surgían como fechas gozne. Es precisamente en la oratoria sagrada, puesta al servicio de la propaganda restauradora, donde podemos encontrar algunos de los más interesantes ejemplos de la construcción de esta narrativa. Véase el caso del Sermão do Apostolo S. Thomé, pronunciado en la capilla real en Lisboa, el día 21 de diciembre de 1645, por el padre jesuita Diogo de Areda ${ }^{19}$. Publicado el año siguiente, el sermón comenzaba por presentar una imagen mesiánica del destino histórico del reino de Portugal, nacido para continuar la conquista espiritual de oriente, que fuera inaugurada por el «Apóstol de las Indias». Apoyado en este lenguaje profético, Diogo de Areda se dedicaba, a continuación, a explicitar el propósito de su prédica: «mostrar las felicidades de los portugueses en Oriente, en el tiempo en que tuvieron reyes propios y naturales, que fue hasta el año 1580 (...) mostrar las miserias, a las que llegaron en el tiempo en que fueron gobernados por reyes castellanos, hasta el año de 1640. Y últimamente (...) mostrar el remedio que se puede esperar en este presente tiempo, en que Dios nos tornó a dar un Rey Portugués»20.

Para este padre jesuita — que testimoniara las fiestas de proclamación de D. João IV en Goa-, la historia del Estado de la India sería entonces la crónica de tres tiempos marcadamente distintos, que correspondían a las tres partes de su texto. El primero equivalía, grosso modo, a las primeras ocho décadas de la presencia portuguesa en Asia, cuando el reino fuera gobernado por «reyes naturales». Esta habría sido una verdadera edad de oro, en la que la liberalidad y el amor de los reyes de Portugal había inspirado a los vasallos a la conquista de tierras

18 Según Rafael Bluteau, autor del primer vocabulario de la lengua portuguesa, el concepto de tiranía indicaría un «domínio ilegítimo, usurpado, ou cruel, \& violento», contrario al bien común, BLUTEAU, 1712-1728 8, 339. Sobre el recurso a este concepto en el marco de la propaganda restauracionista, véase MARQUES, 1989, 32/83.

19 AREDA, 1646. El padre Diogo de Areda S.J. (1599-1671), tenía una gran experiencia de misionado en Oriente, habiendo pasado largos años en la India, donde enseñó Teología en el colegio de Goa y ejerció el cargo de rector del colegio de Chaul. A mediados de la década de 1640 regresó definitivamente al reino, véase MARQUES, 1989 2, 334/335.

20 AREDA, 1646, fol. 6. 
distantes y a la expansión de la fe, motivando las hazañas de capitanes como Vasco da Gama, Duarte Pacheco Pereira o Afonso de Albuquerque ${ }^{21}$. Un periodo de bonanza que, a su entender, habría sido bruscamente interrumpido por la unión dinástica.

El segundo tiempo descrito por el Sermão do Apostolo S. Thomé era el de los sesenta años del que calificaba como «el tiránico yugo castellano», durante los que el Estado de la India había sido gobernado por reyes que, según Diogo de Areda, «no fueron reyes nuestros, porque les faltaba la justicia para serlo, sino apenas señores, que con poder se introdujeron en el reino que no les pertenecía; fueron señores de Portugal y de sus conquistas, y se quisieron hacer señores del mundo extendiendo por todo él su Imperio»22. Para justificar estas acusaciones, Areda se socorría de diversos ejemplos que comprobarían la avidez, prepotencia y desmedida ambición de los monarcas de la casa de Austria. En este sentido, destacaba el abandono de la India a las depredaciones de los enemigos, que había resultado en sucesivos desaires, entre los cuales se contaba la pérdida de Ormuz, ciudad donde «se juntaba lo más rico de Asia, [y] lo más precioso de Europa»23.

Sin embargo, no era tan sólo en las derrotas militares donde, para el padre jesuita, residían los efectos perniciosos de la unión de las coronas. Lamentaba igualmente que se hubiera perdido el celo misionario que había caracterizado las primeras décadas de la presencia portuguesa en Oriente, revelando que se había llegado al punto de ver las iglesias cerradas y los fieles desamparados. No olvidaba tampoco los desmanes de los oficiales de justicia y la codicia de los gobernadores, que sometían a los vasallos a impuestos cada vez más excesivos e injustos $^{24}$. El padre Diogo de Areda recuperaba así los argumentos que habían alimentado la contestación a las políticas reformistas de la primera mitad de la década de 1630, cuyo impacto había coincidido con el virreinato de D. Miguel de Noronha, $4^{\circ}$ conde de Linhares. Desde su llegada a Goa, en otoño de 1629, este virrey había procurado retomar la iniciativa perdida en el escenario asiático, entablando las reformas de las que fuera incumbido por Madrid ${ }^{25}$. Estas se basaban, precisamente, en la remodelación del sistema tributario y en la consolidación de las finanzas del Estado de la India, iniciativas que no dejarían de contar con la oposición de diversos grupos e instituciones, entre las cuales se contaba la Compañía de Jesús.

La narrativa del Sermão do Apostolo S. Thomé tenía como corolario la proclamación de D. João IV, que prometía no sólo el fin de la «tiranía de Castilla» y el retorno a un orden político tradicional, sino también la posibilidad de invertir el ci-

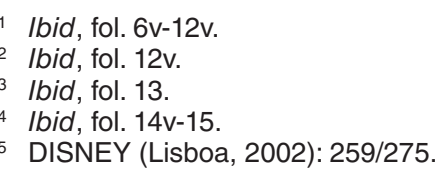


clo de decadencia inaugurado con la agregación a la monarquía hispánica. Siendo así, el padre Diogo de Areda aprovechaba la tercera - y última - parte de su prédica para aconsejar al nuevo rey sobre el procedimiento que éste debería seguir. Haciéndose eco de su experiencia y presentándose como un «testigo de los suspiros, y lágrimas que se derramaron en la India por la continuación de las miserias que allí se padecieron» ${ }^{26}$, el predicador jesuita presentaba algunas propuestas para que el Estado de la India pudiera regresar a su antigua pujanza. Eran éstas, esencialmente, cuestiones de orden práctico, como la urgencia de mantener la tregua con los holandeses para que el Asia portuguesa pudiera recobrar sus fuerzas, y la necesidad de proveer las armadas con navegantes experimentados para evitar el flagelo de los naufragios. Pero no dejaba tampoco de insistir en que el principal intento de los portugueses en Oriente debería ser la "exaltación y dilatación de la fe Católica», y no la obtención de riquezas y beneficios materiales ${ }^{27}$.

Al seguir esta línea de pensamiento, el sermón de Diogo de Areda no se limitaba a enunciar argumentos justificativos de la ruptura con la Monarquía Hispánica. La forma como presentaba la historia del Estado de la India durante los años de la unión dinástica —repensándola a la luz de categorías como «decadencia» y «tiranía»-, confería autoridad y legitimidad a las propuestas que avanzaba para remediar la situación. En este sentido, las imágenes y representaciones que he venido refiriendo a lo largo de las páginas anteriores constituían modalidades de intervención sobre la realidad política, demostrando que la defensa de la causa restauradora podía perfectamente coexistir en el mismo texto con la prosecución de estrategias personales o institucionales.

Algo similar sucedía en el relato del oidor de Cochín. Aunque declaraba que no era su intención enaltecer el papel que había desempeñado en la proclamación de D. João IV, Agostinho de Almeida Gato no dejaba de hacer mención a los caudales que había gastado para demostrar públicamente su alegría por las noticias de la Restauração. Las últimas páginas de su texto son destinadas a la exposición minuciosa del arco triunfal que mandara levantar frente a su casa — del cual decía ser «un hermoso y gran arco, que en todo fue aventajado a los demás»-, juntamente con un altar y un teatro, donde figuras ricamente vestidas representaban los papeles de D. João IV, Francisco de Almeida y Afonso de Albuquerque ${ }^{28}$. Teniendo como telón de fondo la reconstrucción de las pruebas de lealtad ofrecidas por los habitantes de Cochín en las fiestas de proclamación de D. João IV, la relación del oidor no dejaba, con todo, de corresponder a una estrategia discursiva en la que

26 AREDA, 1646, fol. 17v.

27 Ibid, fol. 20-20v.

28 Biblioteca Pública y Arquivo Distrital de Évora, Mss., Códice CXVI/1-23, fol. 20 y ss. Cabe señalar que esta representación de la figura de Don Juan IV fue acompañada por dos personajes prominentes de lo que — mediante el lenguaje del Padre Diego de Areda - había sido la edad de oro del Estado de la India. 
la descripción de las ceremonias surgía como un argumento para elogiar el papel de un protagonista -él mismo- digno de fama, honra y mercedes regias.

\section{CONSIDERACIONES FINALES}

Ante el cuadro bosquejado en las páginas anteriores, no deja de ser curioso que, como destaca Rafael Valladares en su libro Castilla y Portugal en Asia, a lo largo de los siglos XIX y XX la historiografía portuguesa más próxima a los círculos nacionalistas haya reproducido acríticamente las imágenes de la propaganda restauradora, tomándolas como evidencias de que la agregación a la monarquía hispánica había sumergido el Estado de la India en una profunda e irreversible decadencia $^{29}$. En realidad, a mediados del siglo XVII, no todos los portugueses concordaban en cuanto a la forma como debería ser narrada la historia del Estado de la India. Mientras que para los publicistas de la Restauração el fin de la unión dinástica surgía como una promesa de redención de la presencia portuguesa en la India, para hombres como Manuel de Faria e Sousa —autor de Ásia Portuguesa y uno de los muchos portugueses que permanecieron fieles a la monarquía hispánica-, 1640 representaba literalmente el fin de la historia. Por eso mismo, en el último capítulo de su obra, relativo al virreinato de D. João da Silva Telo, conde de Aveiras, Faria e Sousa se limitaba a informar al lector de que: «del virrey João da Silva Telo, de cuya calidad y canas se pueden esperar aciertos, hablarán escritos venideros, porque él empieza su tarea cuando yo concluyo la mía, por terminar el fatal año de 1640, que es el término de este mi cuidado» 30 .

A modo de conclusión, podemos así constatar que, para los textos que buscaban legitimar la coyuntura nacida del golpe de 1 de diciembre de 1640, el pasado reciente del Estado de la India se constituía como una referencia fundamental. De hecho, la destitución de un monarca reinante no podría dejar de ser problemática en una cultura política que enfatizaba la armonía de los lazos que unían al rey y sus vasallos. En este sentido, la ruptura suscitó la aparición de estrategias discursivas que interpretaron la coyuntura sufrida por los portugueses en Asia a la luz de un lenguaje basado en tópicos determinantes en el imaginario y en la cultura política contemporánea, como «decadencia» y «tiranía». Al retratar la rebelión como un desenlace natural y deseado por todos los portugueses que servían en la India, los autores del Sermão do Apostolo S. Thomé y de los Trivmfos festivaes no hacían sino alinear sus intereses con los de la nueva Casa Real, interpretando el fin de la unión dinástica a la luz de sus experiencias locales y presentándose como los agentes de la construcción del nuevo orden político en el Estado de la India.

\footnotetext{
29 VALLADARES, 2001, 1/2.
}

30 FARIA E SOUSA, 1947, 457. 


\section{BIBLIOGRAFÍA}

AMES, Glenn, Renascent empire? The House of Braganza and the quest for stability in portuguese moonson Asia, c. 1640-1683, Ámsterdam, Amsterdam University Press, 2000.

AREDA, Diogo de, Sermão do Apostolo S. Thomé, que pregou o R.P. Diogo de Areda da Companhia de Jesus em seu próprio dia, na Capella Real de Sua Magestade aos 21 de Dezembro, Lisboa, Oficina de Domingos Lopes Rosa, 1646.

BARROS, Edval de Souza, Negócios de tanta importância. O conselho Ultramarino e a disputa pela condução da guerra no Atlântico e no Índico (1643-1661), Lisboa, CHAM, 2008.

BLUTEAU, Rafael, Vocabulário Portuguez, \& Latino, Coimbra, Colégio das Artes da Companhia de Jesus, 1712-1728.

BOXER, Charles, A aclamação de D. João IV em Goa e em Macau. Relações contemporâneas reeditadas e anotadas, Lisboa, Tipografia de José Fernandes Júnior, 1932.

CHATURVEDULA, Nandini, Imperial Excess: Corruption and Decadence in Portuguese India (1660-1706), Nueva York, Columbia University, 2010.

CORTESÃO, Jaime, "A geografia e a economia da Restauração», Teoria geral dos Descobrimentos portugueses, Lisboa, Livros Horizonte, 1984.

DISNEY, Anthony, «The Fiscal Reforms of Viceroy Linhares at Goa», Anais de História de AlémMar, III (Lisboa, 2002): 259/275.

ELLIOTT, John, «Self-perception and decline in early seventeenth century Spain», Past \& Present, 74 (Oxford, 1977): 41/61.

FARIA E SOUSA, Manuel de, Ásia Portuguesa, vol. VI, Lisboa, Civilização, 1947.

GRUZINSKI, Serge, Les quatres parties du monde. Histoire d'une mondialisation, París, Éditions de La Martinière, 2004.

LAVALLÉ, Bernard, "O rumor anti-português da Cidade do Panamá», en Sandra Jatahy Pasavento y Frédérique Langue (eds.), Sensibilidades na História. Memórias singulares e identidades sociais, Porto Alegre, UFRGS, 2007, 181/203.

MARQUES, João Francisco, A parenética portuguesa e a Restauração, 1640-1668. A revolta e a mentalidade, vol. 2, Oporto, INIC, 1989.

SCHWARTZ, Stuart, “Pânico nas Índias: a ameaça portuguesa ao Império espanhol, 1640-1650», Da América Portuguesa ao Brasil. Estudos históricos, Lisboa, Difel, 2003.

SKINNER, Quentin, «Princípios Morais e Mudança Social», Visões da Política. Sobre os métodos históricos, Lisboa, Difel, 2005.

SUBRAHMANYAM, Sanjay, O Império Asiático Português. Uma história política e económica, Lisboa, Difel, 1995.

TAVERNIER, Jean-Baptiste, Les Six Voyages de Jean Baptiste Tavernier, écuyer baron d'Aubonne, qu'il a fait en Turquie, en Perse, et aux Indes, 2 vols., París, Gervais Clouzier, 1676.

VALLADARES, Rafael, Castilla y Portugal en Asia (1580-1680). Declive imperial y adaptación. Leuven, Leuven University Press, 2001.

WINIUS, George, A Lenda Negra da Índia Portuguesa. Diogo do Couto, os seus contemporâneos e o Soldado Prático, Lisboa, Antígona, 1994.

XAVIER, Ângela Barreto, A Invenção de Goa. Poder Imperial e Conversões Culturais nos Séculos XVI e XVII, Lisboa, ICS, 2008. 
